\title{
Preliminary Examination of International Students' Adjustment and Loneliness Related to Electronic Communications.
}

Timothy B. Smith

Brigham Young University, tbs@byu.edu

David A. Shwalb

Brigham Young University

Follow this and additional works at: https://scholarsarchive.byu.edu/facpub

Part of the Counseling Psychology Commons

\section{Original Publication Citation}

Smith, T. B., \& Shwalb, D. A. (2007). Preliminary examination of international students' adjustment and loneliness related to electronic communications. Psychological Reports, 100, 167-170.

\section{BYU ScholarsArchive Citation}

Smith, Timothy B. and Shwalb, David A., "Preliminary Examination of International Students' Adjustment and Loneliness Related to Electronic Communications." (2013). Faculty Publications. 2001.

https://scholarsarchive.byu.edu/facpub/2001 


\section{Running Head: INTERNATIONAL STUDENT ADJUSTMENT}

Smith, T. B., \& Shwalb, D. A. (2007). Preliminary examination of international students' adjustment and loneliness related to electronic communications. Psychological Reports, $100,167-170$.

Preliminary Examination of International Students’ Adjustment and Loneliness related to Electronic Communications ${ }^{1}$

Timothy B. Smith and David A. Shwalb Brigham Young University

${ }^{1}$ Correspondence concerning this manuscript may be directed to Timothy B. Smith, Department of Counseling Psychology and Special Education, Alliances for the Strength of Youth, 340 MCKB, Brigham Young University, Provo, UT 84602, e-mail: tbs@byu.edu. 
Summary. Electronic communication (e.g., e-mail, internet) may facilitate international students' adjustment through contacts maintained with their native country. In the present study, the scores of 45 international students on a measure of adjustment and the Revised UCLA Loneliness Scale were significantly associated with their electronic communications involving their native country but not with general internet or e-mail use. International students' scores on the Multigroup Ethnic Identity Measure were positively correlated with their amount of contact with people in their native country but were not correlated with scores on the measures of adjustment or loneliness. 


\section{A Preliminary Examination of International Students’ Adjustment}

and Loneliness related to Electronic Communications

Contemporary electronic means of communication (e-mail, electronic chat, internet sites, etc.) allow international students rapid, low-cost means of correspondence with and information about their native country. Cemalcilar, Falbo, and Stapleton (2005) have theorized that electronic communications facilitate international students' adjustment to their new environment because electronic communications help to maintain ongoing contact with the students' existing support networks. Those authors also proposed that international students’ electronic communications with their native country may enhance their sense of ethnic identity, with strong ethnic identity being related to the frequency and utility of those contacts. However, few other studies have evaluated these assertions.

In one study (Kline \& Liu, 2005), international student e-mail usage was positively associated with adjustment but was not related to the level of student acculturation. Furthermore, the students' e-mail communications were less relevant to their adjustment than open telephone communications. In another study (Ye, 2006), online communications with individuals from the participants’ own ethnic group were positively associated with adjustment to the United States, with participants with strong ethnic identity (new arrivals) benefiting most from this kind of support. All three studies that have addressed this topic (Cemalcilar et al., 2005; Kline \& Liu, 2005; Ye, 2006) involved participants recruited via e-mail or internet sites, which sampling procedure may have disproportionately attracted participants who already use electronic communications extensively. We therefore sought to clarify the nature of the association between electronic communications, ethnic identity, and adjustment in a sample of international students recruited through general solicitations across campus. We also sought to investigate a 
negative correlate of adjustment, loneliness, because extensive computer usage may be related to social isolation.

We hypothesized that international students’ ethnic identity and electronic communications with their native country would both be positively associated with their adjustment to living in the United States and inversely associated with their feelings of loneliness. We also hypothesized that ethnic identity would moderate the association between electronic communications with participants' native country and their adjustment and loneliness, with participants with strong ethnic identification benefiting most from electronic communications with their native country.

Method

Forty-five international students attending a state university located in the mid-west United States were recruited through advertisements placed across campus that explicitly solicited international student volunteers. Respondents consisted of 57\% women and 43\% men, with ages ranging from 18 to 40 and an average age of 25.7 years $(S D=5.3)$. Respondents had resided in the U.S. for an average of 2 years, with 75\% originating from Asia (Taiwan, China, etc.), 13\% from Europe (France, etc.), 7\% from Africa (Sudan, etc.), and 5\% from Canada. All volunteers completed a statement of informed consent and a survey containing an open-ended question asking them to "List the most helpful emotional supports in your adjustment to living in this country (the Unites States),” along with (1) the Multigroup Ethnic Identity Measure (Phinney, 1992) (example item: “I feel a strong attachment towards my own ethnic group”); (2) an 8-item version of the Revised UCLA Loneliness Scale (Russell, Peplau, \& Cutrona, 1980) (example item: “I feel isolated from others”); and (3) a 15-item measure of Adjustment (example reverse-scored item: "I have had too many problems in this country") that was developed by the 
authors to specifically evaluate participants' experiences living in the United States. The internal consistency (alpha) coefficients obtained for these three measures were .84, .88, and .90, respectively. Participants also reported their usage of the internet and e-mail (total time spent using a computer each week, percentage of time spent using the internet and e-mail when using computers, number of e-mails sent/received each week, and usage in communicating with their home country) and their time spent socializing in person vs. using a computer.

\section{Results}

Participants reported that the most important sources of support for their adjustment to the United States were, in order of importance: friends, emotional/psychological coping strategies (e.g., positive thinking, assertiveness), beneficial aspects of the American lifestyle (e.g., access to resources, freedom of personal expression), family members, university teachers/personnel, and host/sponsor families in the United States. No participant mentioned computer usage or electronic communications as an important means of support.

Pearson correlations between scores on the Multigroup Ethnic Identity Measure and the measures of Adjustment and Loneliness were of small magnitude, .13 and -.14 respectively ( $p>$ .10). As seen in Table 1, participants’ computer usage and their percentages of time spent using internet and e-mail were also not significantly associated with the measures of Adjustment, Loneliness, or Ethnic Identity. However, when specifically used to keep in contact with their native country, internet and e-mail usage were negatively correlated with Loneliness scores but positively correlated with Adjustment and Ethnic Identity scores. Participants’ time spent socializing in person vs. using a computer was positively associated with Adjustment scores and inversely associated with Loneliness scores but not associated with Ethnic Identity. 
To evaluate whether participant scores on the Multigroup Ethnic Identity Measure moderated the association between electronic communications (internet and e-mail) with their native country and scores on the measures of Adjustment and Loneliness, we conducted separate regression models predicting scores on these two measures. For both models, we centered the predictor variables of e-mail and internet contact with their native country along with scores on the Multigroup Ethnic Identity Measure and then subsequently added the interaction terms. The multiple regression model predicting Adjustment scores accounted for $12 \%$ of the variance but did not reach statistical significance $(F=1.0, p=.41)$. The model predicting Loneliness scores accounted for $28 \%$ of the variance $(F=2.8, p=.03)$. The only predictor variable in this model that reached statistical significance was e-mail contact with people in the students' native country (beta $=-.50, p=.005)$. The interaction terms did not reach statistical significance ( $p>$ .10), suggesting that participants' ethnic identity did not moderate the association.

\section{Discussion}

Relocated away from their primary social support network, international college students may benefit from the many advantages of electronic communications (no or minimal cost, easy access, speed, etc.). The results of this study provide some evidence that the use of electronic communications to maintain contact with their native country is positively associated with international student adjustment. Notably, e-mail contact with people from their native country is strongly inversely associated with reported loneliness. However, participants did not spontaneously list electronic communications as an important means of support, and the time they spent socializing in person was more highly correlated with adjustment than time spent using computers. Previous studies have also found that personal contacts are associated with greater adjustment than electronic communications (e.g., Kline \& Liu, 2005). 
Although previous research has shown that international students’ ethnic identity is associated with successful adjustment (e.g., Cemalcilar et al., 2005), our results did not replicate that finding. In our study, participants’ ethnic identity was positively correlated with electronic correspondence (e-mail and internet) with their home country but was not associated with their adjustment or loneliness scores. In our regression models we found no evidence that ethnic identity scores moderated the association between electronic communications and either Adjustment or Loneliness scores.

Two major limitations of the present study are the correlational design used and the small number of participants that restricted the statistical power of our regression models. Nevertheless, our recruitment of participants through general announcements posted across campus was intended to solicit a more representative sample of international students' computer usage than other studies' samples recruited through e-mail and the internet (Cemalcilar et al., 2005; Kline \& Liu, 2005; Ye, 2006). Other notable limitations of our study include data collection from a single institution of higher learning and the restricted geographical origin of the sample, with most participants originating from Asia. Additional research is needed to confirm these findings among other samples and across other settings using more robust designs. 


\section{References}

Cemalcilar, Z., Falbo, T., \& Stapleton, L.M. (2005). Cyber communication: A new opportunity for international students' adaptation? International Journal of Intercultural Relations, 29, 91-110.

Kline, S.L. \& Liu, F. (2005). The influence of comparative media use on acculturation, acculturative stress, and family relationships of Chinese international students. International Journal of Intercultural Relations, 29, 367-390.

Phinney, J.S. (1992). The multigroup ethnic identity measure: A new scale for use with diverse groups. Journal of Adolescent Research, 7, 156-176.

Russell, D., Peplau, L. A., \& Cutrona, C. E. (1980). The revised UCLA Loneliness Scale: Concurrent and discriminant validity evidence. Journal of Personality and Social Psychology, 39, 472-480.

Ye, J. (2006). Traditional and online support networks in the cross-cultural adaptation of Chinese international students in the United States. Journal of Computer-Mediated Communication, 11, 863-876. 
Table 1

Bivariate Correlations between Aspects of Electronic Communication and Scores on Measures of Adjustment, Loneliness, and Ethnic Identity.

\begin{tabular}{lcccc}
\hline \multicolumn{1}{c}{ Measure } & & & \\
& Adjustment & Loneliness & Ethnic \\
Item & Scale & Scale & Identity \\
& & & & \\
& & -.07 & .28 & -.09 \\
Hours Spent on a Computer Weekly & -.19 & .21 & .08 \\
Percent of Computer Time Spent Using Internet & .02 & -.24 & .15 \\
Percent of Computer Time Spent Using E-mail & .17 & -.28 & $.32^{*}$ \\
Internet Use to Keep in Contact with Native Country & $.35^{*}$ & $-.51^{* *}$ & $.35^{*}$ \\
E-mail Use to Keep in Contact with Native Country & .16 & $-.37^{*}$ & $.31^{*}$ \\
Number of E-mails Sent and Received Weekly & $.42^{*}$ & $-.37^{*}$ & .01 \\
\hline
\end{tabular}

$* p<.05, * * p<.001$ 